\title{
Cardiac tamponade: contrast reflux as an indicator of cardiac chamber equalization
}

\author{
Foeke Jacob Harmen Nauta, Wernard Aat Antoine Borstlap, Michael Stella and Zain Khalpey ${ }^{*}$
}

\begin{abstract}
Background: Traumatic hemopericardium remains a rare entity; it does however commonly cause cardiac tamponade which remains a major cause of death in traumatic blunt cardiac injury.

Objectives: We present a case of blunt chest trauma complicated by cardiac tamponade causing cardiac chamber equalization revealed by reflux of contrast.

Case report: A 29-year-old unidentified male suffered blunt chest trauma in a motor vehicle collision. Computed tomography (CT) demonstrated a periaortic hematoma and hemopericardium. Significant contrast reflux was seen in the inferior vena cava and hepatic veins suggesting a change in cardiac chamber pressures. After intensive treatment including cardiac massage this patient expired of cardiac arrest.
\end{abstract}

Conclusion: Reflux of contrast on CT imaging can be an indicator of traumatic cardiac tamponade.

Keywords: Cardiac tamponade, Hemopericardium, Blunt trauma, Contrast reflux, Cardiac hemodynamics

\section{Background}

Traumatic cardiac tamponade remains a deadly, but rare, reason for presentation to the emergency department [1]. Its main cause in trauma patients is penetrating chest injury (80-90\%) and it occurs in only $10 \%$ of blunt chest trauma injuries. Thoracic injuries account for approximately $25 \%$ of trauma related deaths and are a contributing factor in an additional $25 \%$ of deaths in the United States annually [1]. As it is typical for acute trauma, fast and accurate diagnostics are crucial. We present a case of blunt chest trauma including cardiac tamponade revealed by contrast reflux at CT.

\section{Case presentation}

A 29-years-old unidentified male suffered multiple blunt trauma in a severe motor vehicle collision. On suspicion of intracranial injury due to left sided globe rupture, FAST exam was skipped and the patient was rushed to CT. After intravenous administration of contrast, axial CT (Figure 1) demonstrated bilateral pneumothoraces, periaortic hematoma and pulmonary contusion. Coronal

\footnotetext{
* Correspondence: zkhalpey@partners.org

The University of Arizona Medical Center - University Campus, 1501 North Campbell Avenue Tucson, AZ 85724, USA
}

view (Figure 2) showed mild right sided deviation of the trachea, pseudoaneurysm of the descending aorta and hemopericardium. Remarkable contrast reflux was seen into the inferior vena cava (IVC) and hepatic veins. This phenomenon was presumably caused by equalization of cardiac chamber pressures typical of tamponade. Even though emergent thoracotomy following blunt trauma carries an overall survival rate of only 1-2\% [2], after the loss of vital signs, emergent thoracotomy was performed and 2.5 liters of pericardial blood was found originating from a right atrial tear. This case shows that the use of contrast in CT can reveal changes in cardiac chamber pressures possibly indicating traumatic cardiac tamponade.

\section{Discussion}

Several studies have described the relationship between IVC contrast reflux and several morbidities (pulmonary hypertension, tricuspid regurgitation and right ventricular systolic dysfunction) [3-5]. Dusaj et al. [6] demonstrated the hemodynamic potential of Coronary CT angiography (CTCA). Quantification of IVC and SVC contrast characteristics during CTCA provides a quick, feasible and accurate method of estimating right atrial and ventricular response. Their findings correlated with 


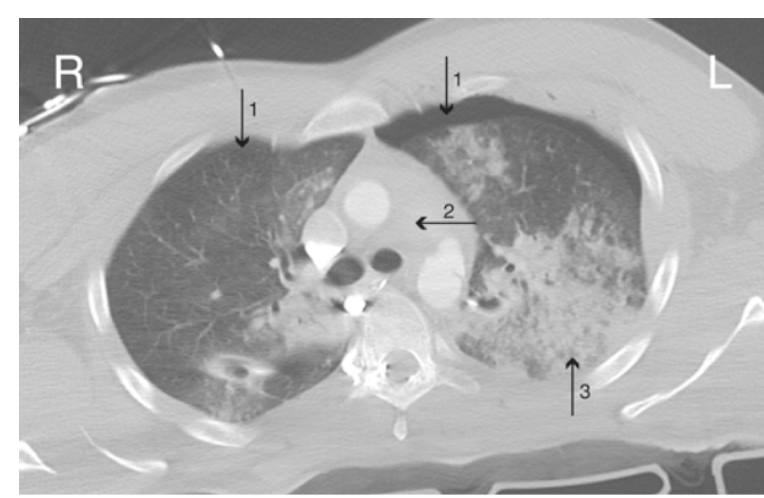

Axial contrast $\mathrm{CT}$ chest

Figure 1 Axial contrast CT chest showed bilateral pneumothoraces (1), periaortic hematoma (2) and pulmonary contusion (3).

echocardiographic estimations of right atrial and right ventricular pressures. Similarly, we have found that contrast reflux in the IVC, SVC and hepatic veins correlates with acute hemodynamic changes associated with cardiac tamponade.

\section{Conclusion}

This case emphasizes the diagnostic potential of contrast enhanced CT of the chest to characterize acute cardiovascular physiology, particularly in blunt chest trauma.

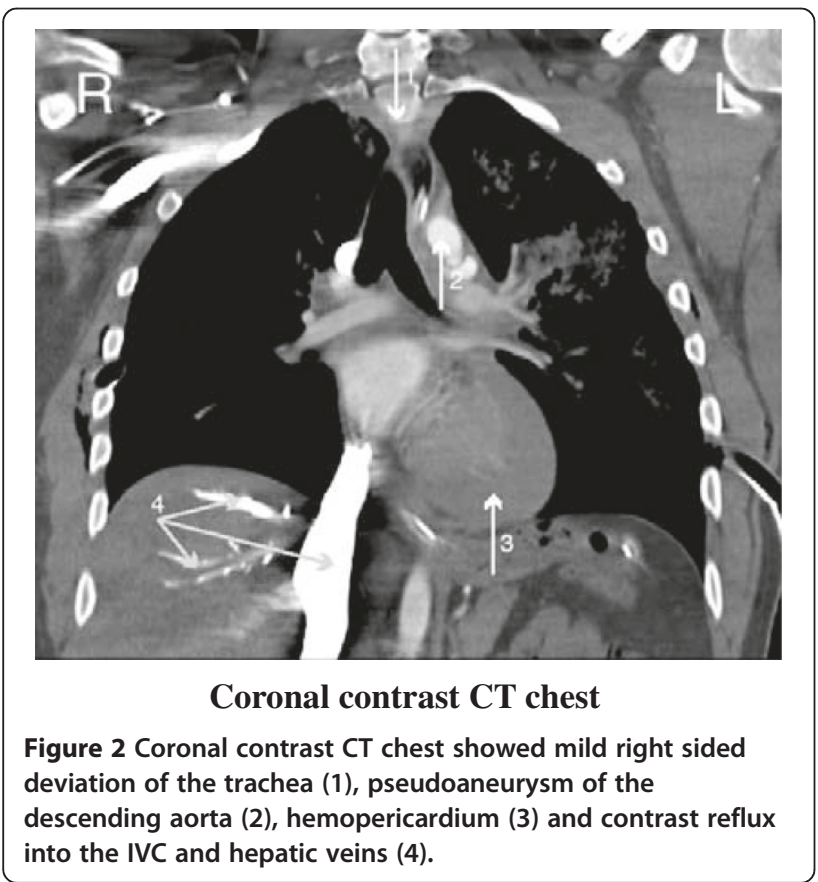

\section{Consent}

Unfortunately patient deceased and no medical consent was obtained.

\section{Abbreviations}

CT: Computed tomography; FAST: Focused assessment with sonography for trauma; IVC: Inferior vena cava; CTCA: Coronary CT angiography;

SVC: Superior vena cava.

\section{Competing interest}

The author(s) declare that they have no competing interest.

\section{Acknowledgements}

None.

\section{Authors' contributions}

FN and WB reviewed the literature, FN wrote the manuscript. ZK, WB and MS edited the text. MS supplied and described the images. All authors read and approved the final manuscript.

\section{Author's information}

FN and WB are clinical research trainees. ZK is the supervising chief resident cardiac surgery and MS is a radiologist.

Received: 29 December 2011 Accepted: 31 May 2012

Published: 31 May 2012

\section{References}

1. Yamamoto L, Schroeder C, Morley D, Beliveau C: Thoracic trauma: the deadly dozen. Crit Care Nurs Q 2005, 28(1):22-40.

2. Hunt PA, Greaves I, Owens WA: Emergency thoracotomy in thoracic trauma-a review. Injury 2006, 37(1):11-19.

3. Groves AM, Win T, Charman SC, Wisbey C, Pepke-Zaba J, Coulden RA: Semiquantitative assessment of tricuspid regurgitation on contrast-enhanced multidetector CT. Clin Radiol 2004, 59(8):715-719.

4. Yeh BM, Kurzman P, Foster E, Qayyum A, Joe B, Coakley F: Clinical relevance of retrograde inferior vena cava or hepatic vein opacification during contrast-enhanced CT. AJR Am J Roentgenol 2004, 183(5):1227-1232.

5. Collins MA, Pidgeon JW, Fitzgerald R: Computed tomography manifestations of tricuspid regurgitation. Br J Radio/ 1995, 68(814):1058-1060

6. Dusaj RS, Michelis KC, Terek M, Sanai R, Mittal R, Lewis JF, Zeman RK, Choi BG: Estimation of right atrial and ventricular hemodynamics by $\mathrm{CT}$ coronary angiography. J Cardiovasc Comput Tomogr 2011, 5(1):44-49.

doi:10.1186/1749-8090-7-48

Cite this article as: Nauta et al:: Cardiac tamponade: contrast reflux as an indicator of cardiac chamber equalization. Journal of Cardiothoracic Surgery 2012 7:48.

\section{Submit your next manuscript to BioMed Central and take full advantage of:}

- Convenient online submission

- Thorough peer review

- No space constraints or color figure charges

- Immediate publication on acceptance

- Inclusion in PubMed, CAS, Scopus and Google Scholar

- Research which is freely available for redistribution
Biomed Central 